\title{
Фотоэлектрические AlGaAs/GaAs-преобразователи излучения тритиевых радиолюминесцентных ламп
}

\author{
(C) В.П. Хвостиков, В.С. Калиновский, С.В. Сорокина, М.З. Шварц, Н.С. Потапович, \\ О.А. Хвостикова, А.С. Власов, В.М. Андреев
}

Физико-технический институт им. А.Ф. Иоффре Российской академии наук, 194021 Санкт-Петербург, Россия

E-mail: vlkhv@scell.ioffe.ru

(Получена 25 июня 2018 г. Принята к печати 6 июля 2018 г.)

\begin{abstract}
Разработаны и изготовлены источники электропитания на основе фотоэлектрических преобразователей и радиолюминесцентных тритиевых ламп с голубым и зеленым свечением. Методом низкотемпературной эпитаксии из жидкой фазы получены гетероструктуры $(p-n) \mathrm{Al}_{x} \mathrm{Ga}_{1-x} \mathrm{As}$ с различными значениями ширины запрещенной зоны $\left(E_{g}=1.4-1.9\right.$ эВ) и составом активной области $(x=0.1-0.35)$. Фотоэлектрический преобразователь площадью $S=0.12 \mathrm{~cm}^{2}$ при облучении зеленой тритиевой лампой (длина волны $\lambda=550$ нм) характеризуется плотностью тока короткого замыкания $180 \mathrm{HA} / \mathrm{cm}^{2}$ и выходной электрической мощностью $>100 \mathrm{HBT} / \mathrm{cm}^{2}$.
\end{abstract}

DOI: $10.21883 /$ FTP.2018.13.46881.8942

\section{1. Введение}

Для многих практических применений (в космической и подводной технике, в имплантатах-кардиостимуляторах, биологических датчиках и т.д.) требуется автономный и компактный источник электропитания с длительным ресурсом работы. Радиационное воздействие на фотоэлектрический преобразователь (ФЭП) или радиолюминесцентные материалы открывает возможности создания источников электропитания на бетавольтаическом эффекте [1-7]. Источник электропитания на основе излучения радиолюминесцентных ламп может оказаться менее эффективным, чем прямое использование бетараспада изотопов, однако будет обладать существенным преимуществом - сниженным повреждающим воздействием бетаизлучения на фотоактивную область ФЭП. Также следует учесть, что генерация электронно-дырочных пар в бетавольтаическом преобразователе осуществляется не только в узкозонной активной области, но и в широкозонном пассивирующем слое гетероструктуры, что также негативно сказывается на кпд прямого преобразования бетаизлучения.

Большое значение имеет выбор изотопа, активирующего подсветку люминофора в радиолюминесцентных лампах. Анализ применяемых радиоактивных материалов (см. таблицу) показывает высокий потенциал трития $[4,6]$ за счет большого периода полураспада (12 лет), безопасности в использовании и доступности. В тритиевых лампах изотоп помещается в герметичную капсулу, на внутреннюю поверхность которой наносится слой радиолюминофора. Следует подчеркнуть, что яркость таких ламп зависит от толщины люминофорного покрытия, геометрической формы колбы, давления газа, характеристик дополнительных отражающих слоев. При прочих равных условиях зеленое свечение всегда оказывается интенсивнее красного и синего.

Особенностью фотоэлектрического преобразователя радиолюминесцентного излучения является работа в условиях низкой освещенности, поэтому предъявляемое к ним основное требование - низкие значения токов утечки и насыщения. Высокий потенциал в качестве полупроводникового материала для таких ФЭП имеют гетероструктуры AlGaAs/GaAs [1,2]. По сравнению с кремнием GaAs позволяет уменьшить на 8 порядков ток насыщения (значения тока насыщения для $\mathrm{Si}$ составляют $10^{-12} \mathrm{~A} \cdot \mathrm{cm}^{-2}$, для $\left.\mathrm{GaAs}-10^{-20} \mathrm{~A} \cdot \mathrm{cm}^{-2}[8]\right)$. Увеличение ширины запрещенной зоны $E_{g}$ при формировании $p$-n-перехода в материале $\mathrm{AlGaAs}$ обеспечивает снижение токов насыщения по сравнению с GaAs, что способствует повышению кпд и радиационной стойкости $[8,9]$ фотоэлектрического преобразования излучения. При использовании в фотоактивной области приборных гетероструктур твердых растворов $\mathrm{AlGaAs}$ с контролируемо изменяемой $E_{g}$ появляется возможность оптимального согласования спектра люминесценции радиолюминофора со спектральной чувствительностью ФЭП.

Для создания приборных гетероструктур использовался метод эпитаксии из жидкой фазы (ЖФЭ). Равновесные условия кристаллизации, в которых проводятся процессы ЖФЭ, способствуют созданию полупроводниковых слоев с низкой концентрацией собственных дефектов и высоким кристаллографическим качеством. Настоящая работа посвящена разработке фотоэлектрических источников энергии на основе гетероструктур $\mathrm{AlGaAs} / \mathrm{GaAs}$, преобразующих радиолюминесцентное излучение в синем $(\lambda=460 \mathrm{HM})$ и зеленом $(\lambda=550$ нм $)$ спектральных диапазонах.

\section{2. Гетероструктуры фотоэлектрических преобразователей}

Структура преобразователя люминесцентного излучения включает буферный слой $n$-GaAs, $p$-n-переход в $\mathrm{Al}_{x} \mathrm{Ga}_{1-x} \mathrm{As}(x=0.1-0.35)$, ультратонкий слой 
Сравнение свойств основных изотопов с бетараспадом

\begin{tabular}{l|c|c|c|c|c}
\hline \multicolumn{1}{c|}{ Изотоп } & ${ }^{3} \mathrm{H}$ & ${ }^{147} \mathrm{Pm}$ & ${ }^{90} \mathrm{Sr}$ & ${ }^{90} \mathrm{Y}$ & ${ }^{63} \mathrm{Ni}$ \\
\hline Период полураспада & 12.3 лет & 2.6 года & 29.1 лет & 64.1 ч & 100.1 лет \\
Максимальная энергия $\beta$-частиц, кэВ & 18 & 225 & 540 & 2240 & 67 \\
Средняя энергия $\beta$-частиц, кэВ & 5.7 & 62 & 198 & 930 & 17.4 \\
Удельная радиоактивность, Сi/Г & 9664 & 600 & 140 & 550000 & 59.2 \\
Радиотоксичность & Низкая & Высокая & Высокая & Средняя & Низкая
\end{tabular}

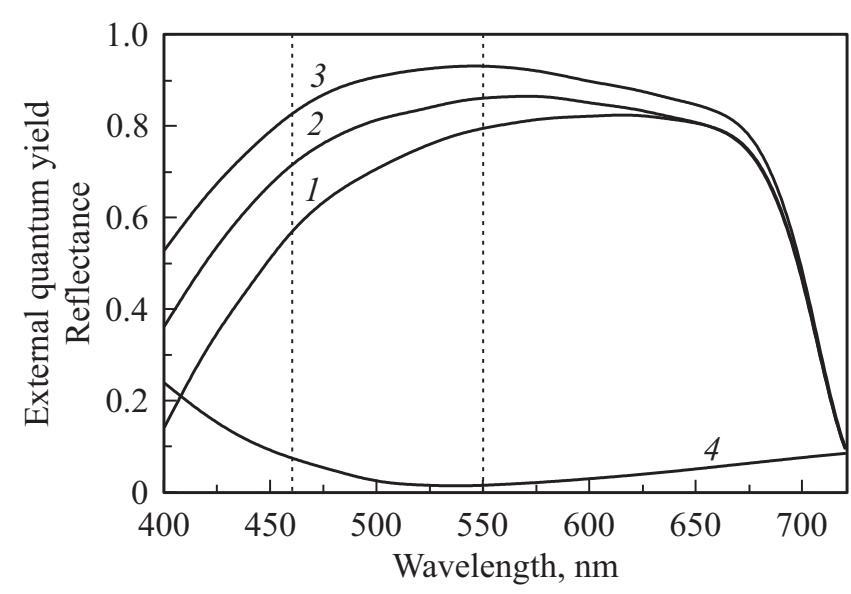

Рис. 1. Спектральные зависимости внешнего квантового выхода фотоответа ФЭП: без травления широкозонного окна толщиной $d=1000 \AA(1)$ и с травлением до толщин $600(2)$, $300 \AA$ (3). 4 - коэффициент отражения при оптимизации для $\lambda=550 \mathrm{HM}$.

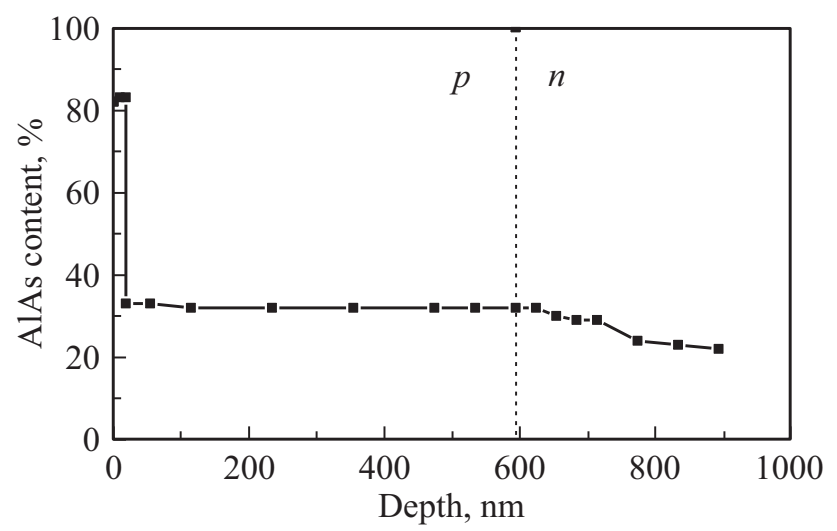

Рис. 2. Распределение содержания AlAs в глубь структуры (полученное на основе измерений спектров рамановского рассеяния) с фронтальным широкозонным слоем $p-\mathrm{Al}_{0.85} \mathrm{Ga}_{0.15} \mathrm{As}$ толщиной $200 \AA$.

широкозонного оптического окна $p$ - $\mathrm{Al}_{0.85} \mathrm{Ga}_{0.15} \mathrm{As}$ и контактный слой $p^{+}$-GaAs (0.1 мкм). Использовались подложки $n$-GaAs c концентрацией носителей заряда $n=2 \cdot 10^{18} \mathrm{~cm}^{-3}$ с формированием тыльного контакта по традиционной для фотоэлементов схеме - осаждением сплошного слоя металла на тыльной стороне подложки. В ряде случаев использовалась полуизолирующая подложка $i$-GaAs с выносом контакта $n$-типа на фронтальную поверхность. Это позволяло без разделения структуры на отдельные ФЭП создавать бетабатарею из последовательно соединенных элементов с высоким выходным напряжением.

Повышение спектральной чувствительности ФЭП достигалось снижением температуры кристаллизации широкозонного окна до $400-500^{\circ} \mathrm{C}$ и его постростовым травлением до толщины $d=100-300 \AA$ с целью получения максимального коэффициента собирания носителей, генерируемых коротковолновым $(\lambda=450-550$ нм $)$ радиолюминесцентным излучением (рис. 1). При $d<100$ нм становятся заметны процессы туннелирования фотогенерированных носителей на поверхность [10], что ухудшает характеристики ФЭП. Глубина залегания $p-n$-перехода не превышала 0.5-1.0 мкм. Пример профиля распределения AlAs по толщине структуры и положение $p-n$-перехода приведены на рис. 2. Данные получены методом рамановской спектроскопии в сочетании с прецизионным травлением образца методом анодного окисления. Антиотражающее покрытие было оптимизировано под облучение синим $(\lambda=460$ нм $)$ или зеленым $(\lambda=550$ нм, кривая 4 , на рис. 1$)$ радиолюминесцентным излучением.

\section{3. Экспериментальные результаты}

Были созданы ФЭП с различным содержанием алюминия и, соответственно, с разными значениями $E_{g}$

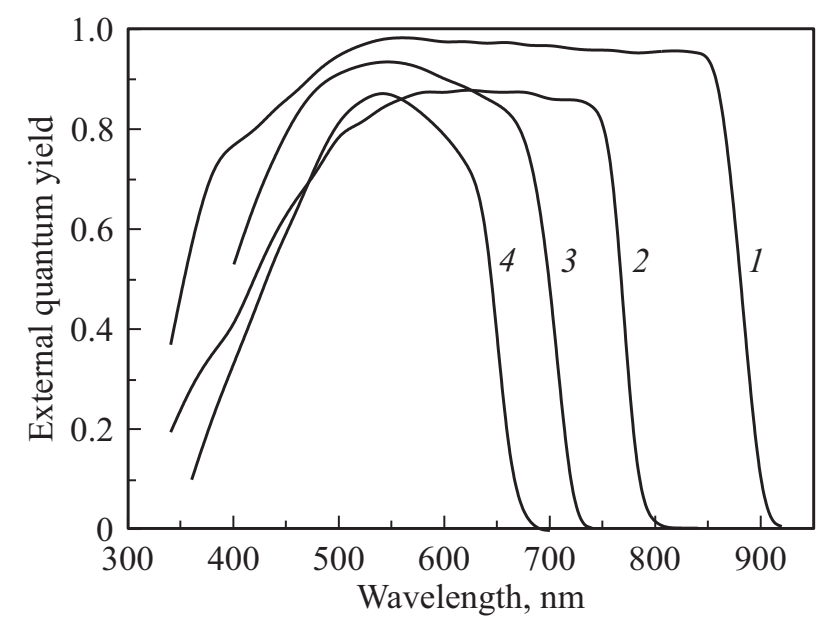

Рис. 3. Спектры фотоответа ФЭП с шириной запрещенной зоны в области $p-n$-перехода $E_{g}=1.4(1), 1.65(2), 1.75$ (3), 1.9 эВ (4) при содержании AlAs в фотоактивных слоях $0,0.18$, $0.26,0.35 \%$, соответственно. 


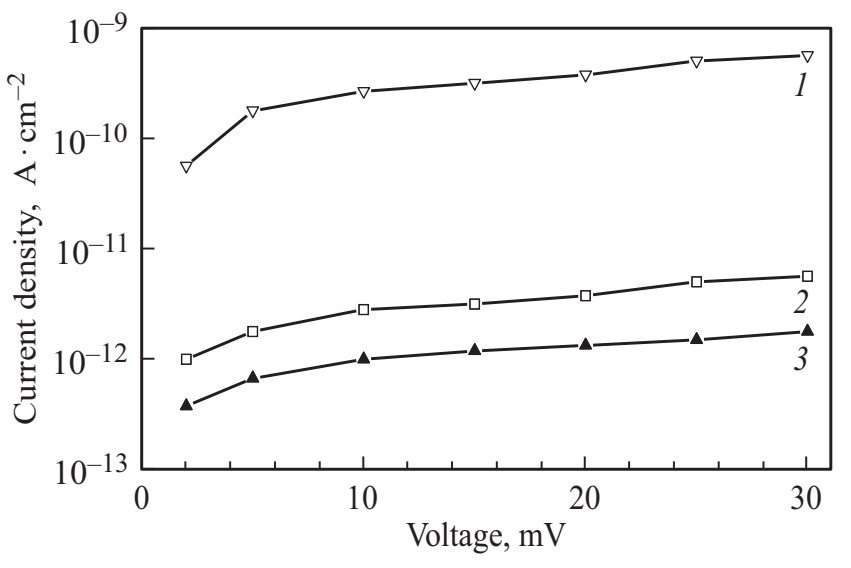

Рис. 4. Темновые ВАХ преобразователей $\left(S=0.12 \mathrm{~cm}^{2}\right)$ с содержанием арсенида алюминия в активной области $\mathrm{Al}_{x} \mathrm{Ga}_{1-x}$ As $x=0$ (1), 0.13 (2), 0.3 (3).
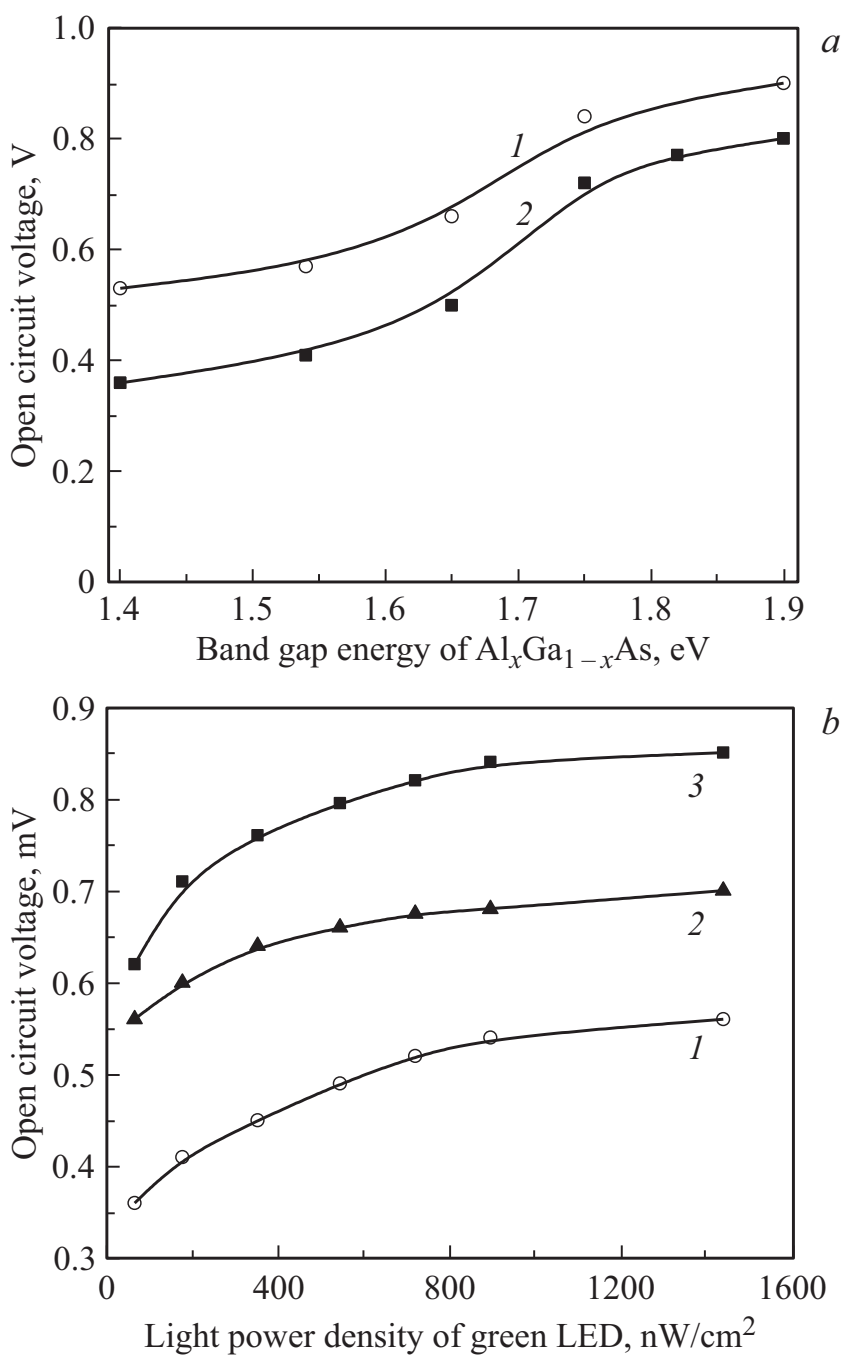

Рис. 5. Зависимость $V_{o c}: a-$ от ширины запрещенной зоны фотоактивной области ФЭП при плотности фототока $10^{-6} \mathrm{~A} / \mathrm{cm}^{2}$ (1, засветка LED), $10^{-7} \mathrm{~A} / \mathrm{cm}^{2}$ (2, возбуждение тритиевой лампой с зеленым свечением); $b$ - от мощности светодиода при $E_{g}=1.43$ (1), $1.82(2), 1.9$ эВ (3).

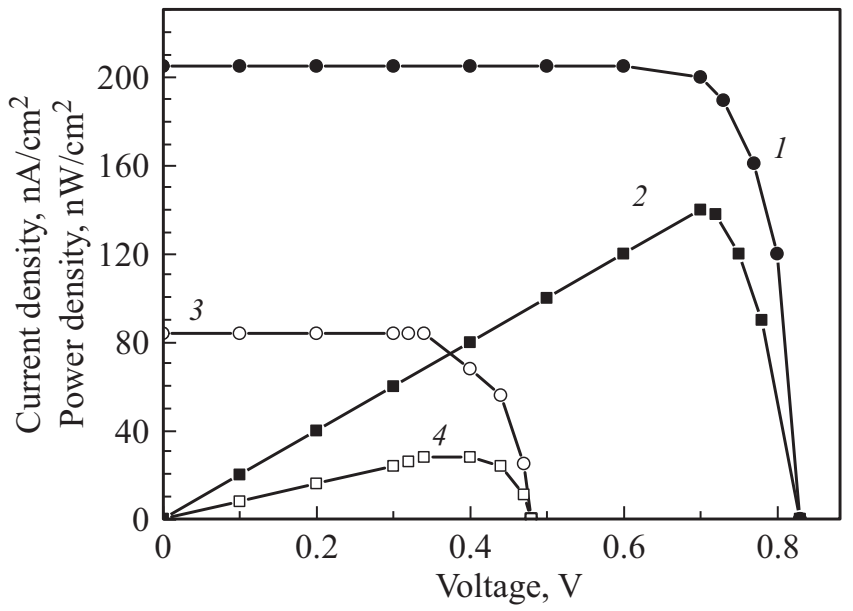

Рис. 6. Нагрузочная характеристика $(1,3)$ и выходная удельная мощность $(2,4)$ ФЭП при освещении зеленым светодиодом $\left(1,2, S=0.12 \mathrm{~cm}^{2}\right)$ и зеленой тритиевой лампой $(3,4$, $\left.S=0.81 \mathrm{~cm}^{2}\right)$.

в активной области (рис. 3). Варьирование состава твердого раствора $\mathrm{Al}_{x} \mathrm{Ga}_{1-x}$ As обеспечивает подстройку спектра фотоответа под длину волны излучения. Так, для люминофоров красного света оптимальным является ФЭП с $E_{g} \approx 1.4-1.6$ эВ (кривые 1 и 2 на рис. 3). Для тритиевых ламп с синим и зеленым свечением оптимальны преобразователи с $E_{g} \approx 1.75$ и 1.9 эВ (кривые 3 и 4 на рис. 3).

При увеличении $E_{g}$ в области $p-n$-перехода возрастает напряжение холостого хода $\left(V_{o c}\right)$, уменьшаются темновые токи и обеспечивается более высокая термостабильность фотопреобразователя. Изменение плотностей темновых токов при варьировании состава активной области ФЭП иллюстрирует рис. 4, где представлены обратные ветви вольт-амперных характеристик (BAX). Значительное снижение значений обратного тока (вплоть до $\sim 10^{-12} \mathrm{~A} / \mathrm{cm}^{2}$ при напряжении $10 \mathrm{MB}$ ) происходит при увеличении содержания AlAs в области $p-n$-перехода до $x=0.3$ (кривая 3).

Зависимость $V_{o c}$ от ширины запрещенной зоны фотоактивной области преобразователя при освещении зеленым светодиодом (LED, кривая 1) или тритиевой лампой (кривая 2) показана на рис. 5, $a$. При плотности фототока $10^{-6} \mathrm{~A} / \mathrm{cm}^{2}$ замена GaAs на $\mathrm{Al}_{0.35} \mathrm{Ga}_{0.65} \mathrm{As}\left(E_{g}=1.9{ }_{\text {э } \mathrm{B})}\right.$ увеличивает $V_{o c}$ от 0.52 до $0.9 \mathrm{~B}$ (рис. 5, $a$, кривая 1 ). При плотности тока $10^{-7} \mathrm{~A} / \mathrm{cm}^{2}$ замена GaAs на твердый раствор $\mathrm{Al}_{0.35} \mathrm{Ga}_{0.65} \mathrm{As}$ повышает значение $V_{\text {ос }}$ от 0.36 до 0.8 В (рис. $5, a$, кривая 2 ).

На рис. 6 представлены нагрузочные ВАХ и зависимости выходной мощности ФЭП при освещении зеленым $(\lambda=550$ нм) светодиодом (кривые 1,2$)$ и зеленой тритиевой лампой (кривые 3,4 ). В образцах малой площади $\left(S=0.12 \mathrm{~cm}^{2}\right)$ при засветке тритиевой лампой плотность тока короткого замыкания $\left(J_{s c}\right)$ и удельная выходная электрическая мощность $\left(P_{0}\right)$ составили $J_{s c}=180 \mathrm{HA} / \mathrm{cm}^{2}$ и $P_{0}=100 \mathrm{HBT} / \mathrm{cm}^{2}$. Для ФЭП площадью $0.8 \mathrm{~cm}^{2}$ при засветке зеленой тритиевой лампой 
была зарегистрирована выходная электрическая мощность $\sim 30 \mathrm{HBT} / \mathrm{cm}^{2}$.

\section{4. Заключение}

Эпитаксией из жидкой фазы с последующим постростовым уменьшением толщины широкозонного окна до $d=0.01-0.03$ мкм получены гетероструктуры $\mathrm{AlGaAs} / \mathrm{GaAs}$ с высокой спектральной чувствительностью к излучению синих $(\lambda=460$ нм $)$ и зеленых $(\lambda=550$ нм $)$ тритиевых ламп. Увеличение содержания AlAs в активной области $\mathrm{Al}_{x} \mathrm{Ga}_{1-x} \mathrm{As}$ от $x=0.1$ до $x=0.25-0.35$ смещает максимум фотоответа в коротковолновую область, обеспечивая эффективное преобразование излучения радиолюминофоров голубого и зеленого свечения, снижение обратных токов и увеличение рабочего напряжения ФЭП. При засветке ФЭП зеленой радиолюминесцентной тритиевой лампой были достигнуты значения фототока до $180 \mathrm{HA} / \mathrm{cm}^{2}$ и удельной мощности до $P_{0} \approx 100 \mathrm{HBT} / \mathrm{cm}^{2}$.

\section{Список литературы}

[1] В.М. Андреев, В.С. Калиновский, В.Р. Ларионов, Е.О. Стругова, В.Д. Румянцев. ФТП, 28 (2), 338 (1994)

[2] В.М. Андреев, В.А. Грилихес, В.Д. Румянцев. Фотоэлектрические преобразование концентрированного солнечного излучения (Л., Наука, 1989).

[3] L.C. Olsen. Proc. 12th Space Photovoltaic Research and Technology Conf. (Cleveland, US, 1992) p. 256.

[4] G.N. Yakubova. Phd thesis (University of Illinois at UrbanaChampaign, 2010).

[5] В. Войтович, А. Гордеев, А. Думаневич. Современная электроника, 6, 10 (2015).

[6] Ch. Thomas, S. Portnoff, M.G. Spencer. Appl. Phys. Lett., 108, 013505 (2016).

[7] А.А. Горбацевич, А.Б. Данилин, В.И. Корнеев, Э.П. Магомедбеков, А.А. Молин. ЖТФ, 86 (7), 94 (2016).

[8] В.М. Андреев, В.С. Калиновский, В.Р. Ларионов, М.М. Миланова, К.Я. Расулов, В.Д. Румянцев, В.П. Хвостиков. Письма ЖТФ, 16 (19), 56 (1990).

[9] V.P. Khvostikov, V.R. Larionov, E.V. Paleeva, S.V. Sorokina, O.I. Chosta, M.Z. Shvarts, N.S. Zimogorova. Proc. 4th Eur. Space Power Conference (Poitiers, France, 1995) v. 2, p. 359.

[10] В.М. Андреев, А.А.Воднев, В.Р. Ларионов, Т.А. Пруцких, В.Д. Румянцев, К.Я. Расулов, В.П. Хвостиков. ФТП, 23 (4), 597 (1988).

Редактор Л.В. Шаронова

\section{AIGaAs/GaAs photovoltaic converters of tritium radioluminescent lamp radiation}

\author{
V.P. Khvostikov, V.S. Kalinovskiy, S.V. Sorokina, \\ M.Z. Shvarts, N.S. Potapovich, O.A. Khvostikova, \\ A.S. Vlasov, V.M. Andreev
}

loffe Institute, 194021 St. Petersburg, Russia

\begin{abstract}
Power supplies based on photovoltaic converters and radioluminescent tritium lamps with blue and green glow have been developed. $\mathrm{Al}_{x} \mathrm{Ga}_{1-x} \mathrm{As} / n$-GaAs $p-n$-heterostructures with band gaps $E_{g}=1.4-1.9 \mathrm{eV}$ and the corresponding compositions of the active region, $x=0.1-0.35$, were obtained by means of low-temperature liquid-phase epitaxy. The photovoltaic converter with the active area of $S=0.12 \mathrm{~cm}^{2}$ under green tritium lamp irradiation (wawelength $\lambda=550 \mathrm{~nm}$ ) revealed a short circuit current density of $180 \mathrm{nA} / \mathrm{cm}^{2}$ and the output power of more than $100 \mathrm{nW} / \mathrm{cm}^{2}$.
\end{abstract}

